\title{
Radionuclide measurement of left ventricular ejection fraction in infants and children
}

\author{
E J BAKER, S V ELLAM, M N MAISEY, M J TYNAN \\ From the Departments of Paediatric Cardiology, Clinical Physics and Bioengineering, and Nuclear Medicine, Guy's \\ Hospital, London
}

SUMMARY The left ventricular ejection fraction was measured in 60 infants and children with congenital heart disease by both the equilibrium gated radionuclide technique and biplane left ventricular cineangiography. The median age of the patients studied was 2.25 years, and 17 were less than 1 year old. The correlation coefficient for the two sets of measurements was good and did not deteriorate in subgroups under 1 year old and with a large left to right shunt. In those infants with a right to left shunt the correlation was weak.

Equilibrium gated radionuclide angiography is a valid and clinically valuable method of measuring left ventricular function in infants and children with congenital heart disease.

Eighty per cent of children with congential heart disease present in the first year of life, ${ }^{1}$ and corrective surgery is being performed increasingly in infants. A technique to measure left ventricular function noninvasively in this age group is potentially very valuable for preoperative assessment and immediate postoperative management of these patients. It would also be important in the assessment of their long term prognosis.

Non-invasive radionuclide angiography has been extensively used to measure left ventricular function in adults. ${ }^{2}$ There are some reports of its use in older children, ${ }^{34}$ but its use in infants has not previously been studied.

First pass radionuclide studies are used to measure the pulmonary to systemic flow ratio in infants and children with left to right shunts. ${ }^{56}$ The left ventricular ejection fraction can be measured simultaneously. ${ }^{37}$ If the radionuclide is given in the form of technetium-99m labelled red blood cells, electrocardiogram gated equilibrium studies can be acquired subsequently without any further dose of radiation. These can also be used for measuring the left ventricular ejection fraction. 489

The aim of this study was to assess the validity of measuring left ventricular ejection fraction by the gated radionuclide technique in infants and children

Requests for reprints to Dr E J Baker, Department of Paediatrics, Guy's Hospital, London SE1 9RT.

Accepted for publication 27 October 1983 with congenital heart disease. We compared these measurements in an unselected group with those obtained by left ventricular cineangiography.

\section{Patients and methods}

\section{STUDY POPULATION}

The study group consisted of 60 children with congenital heart malformations aged 2 weeks to 16 years (median age 2.25 years); 17 were less than 1 year old. All infants and children who were admitted to this unit for clinically indicated diagnostic cardiac catheterisation and radionuclide angiography during the study period were eligible for inclusion. In five children the results have not been included because of poor quality radionuclide studies due to poor red cell labelling efficiency (two cases) and dextrocardia with complex anatomy (three cases), which prevented adequate separation of the left ventricle. The results for all the remaining cases are included. The diagnoses are given in Tables 1 and 2 .

\section{RADIONUCLIDE ANGIOGRAPHY}

The first pass radionuclide study was acquired in the anterior projection. A rapid intravenous bolus of no more than $0.5 \mathrm{ml}$ of technetium-99m labelled red blood cells was given. The patient's blood was labelled in vitro by the Brookhaven method. The dose administered was $430 \mathrm{MBq} / \mathrm{m}^{2}\left(11.6 \mathrm{mCi} / \mathrm{m}^{2}\right)$. The first pass study was used to identify and measure left to right shunts and identify right to left shunts. 
Table 1 Results in patients with a small left to right shunt and no right to left shunt (group 1) and in those with a large left to right shunt and no right to left shunt (group 2)

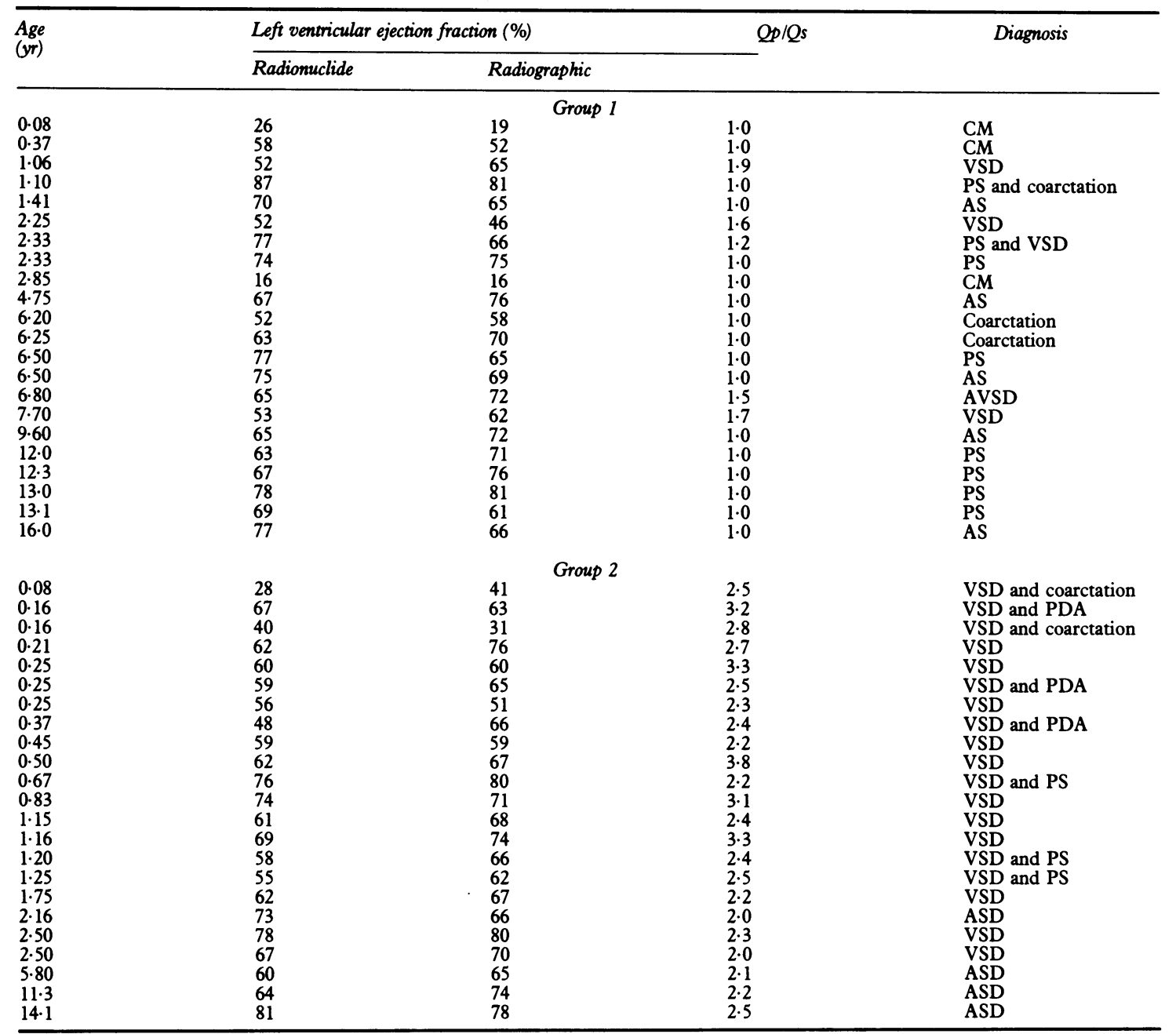

VSD, ventricular septal defect; PDA, persistent ductus arteriosus, PS, pulmonary stenosis; ASD, atrial septal defect; CM, congestive cardiomyopathy; AVSD, atrioventricular septal defect.

After equilibration, electrocardiogram gated radionuclide angiograms were acquired in a modified left anterior oblique projection, the angle being adjusted to give the best separation of the left ventricle from surrounding structures. Data were acquired until a minimum of $3.0 \times 10^{6}$ counts had been obtained using either a Technicare 120 camera linked to a Digital Equipment Corporation Gamma 11 system or an Elscint $215 \mathrm{M}$ mobile gamma camera system. Eighteen or 24 frames were acquired per cardiac cycle on the two systems respectively.

The studies were analysed using an end diastolic left ventricular region of interest, drawn by the operator with the aid of a stroke volume image, and a computer derived diastolic background region of interest lateral and inferior to the left ventricle. This region was adjusted by the operator if considered to be inappropriate. To assess reproducibility 20 cases were each analysed three times, by one operator on two separate occasions and then independently by a second operator.

The estimated whole body absorbed radiation dose of these studies was $0.45 \mathrm{rad}(4.5 \mathrm{mGy})$ for a newborn infant and $0.36 \mathrm{rad}(3.6 \mathrm{mGy})$ for a 16 year old.

\section{CINEANGIOGRAPHY}

Orthogonal biplanar left ventricular cineangiography was performed. A centimetre grid was filmed with the 
Table 2 Results in patients with a right to left shunt

\begin{tabular}{llll}
\hline $\begin{array}{l}\text { Age } \\
\text { (yr) }\end{array}$ & $\begin{array}{l}\text { Lefi ventricular ejection } \\
\text { fraction (\%) }\end{array}$ & Diagnosis \\
\cline { 2 - 3 } & Radionuclide & Radiographic & \\
\hline 0.06 & 56 & 53 & Pulmonary atresia \\
0.29 & 51 & 75 & Complete transposition \\
0.50 & 54 & 68 & Complete transposition \\
1.0 & 73 & 72 & Tetralogy of Fallot \\
1.25 & 83 & 75 & Ventricular septal defect \\
2.0 & 68 & 58 & Tetralogy of Fallot \\
2.41 & 47 & 63 & Tricuspid atresia \\
2.60 & 57 & 70 & Pulmonary stenosis \\
2.90 & 47 & 45 & Tricuspid atresia \\
3.0 & 52 & 65 & Tricuspid atresia \\
3.1 & 48 & 58 & Tricuspid stenosis \\
3.1 & 66 & 71 & Tetralogy of Fallot \\
3.9 & 48 & 49 & Tricuspid atresia \\
11.0 & 58 & 68 & Tricuspid atresia \\
13.6 & 64 & 77 & Tricuspid atresia \\
\hline
\end{tabular}

same film to tube distance as the estimated position of the left ventricle to act as a reference length. The left ventricular area and length at end diastole and end systole were planimetered and the volumes calculated by the area length method. ${ }^{10}$ Extrasystoles and post extrasystolic beats were excluded from the analysis.

\section{STATISTICAL ANALYSIS}

Statistical analysis of the results was performed using linear regression analysis of the radionuclide and radiographic ejection fractions. Individual correlations were compared using an $\mathrm{F}$ test of the variance. Reproducibility was assessed by correlation of the first measurement of the ejection fraction with the second by the same observer and also with the value obtained by the second observer. The null hypothesis was rejected when $\mathrm{p}>0.05$.

Table 3 Results of reproducibility study

\begin{tabular}{llc}
\hline Operator 1 & & Operator 2 \\
\hline 21 & 23 & 19 \\
82 & 72 & 68 \\
66 & 68 & 71 \\
72 & 73 & 75 \\
70 & 67 & 65 \\
75 & 73 & 69 \\
79 & 86 & 84 \\
40 & 44 & 59 \\
54 & 76 & 54 \\
42 & 44 & 48 \\
54 & 48 & 42 \\
70 & 66 & 76 \\
49 & 49 & 76 \\
14 & 11 & 13 \\
16 & 11 & 13 \\
47 & 50 & 55 \\
65 & 68 & 73 \\
11 & 10 & 11 \\
48 & 51 & 58 \\
47 & 53 & 56 \\
\hline
\end{tabular}
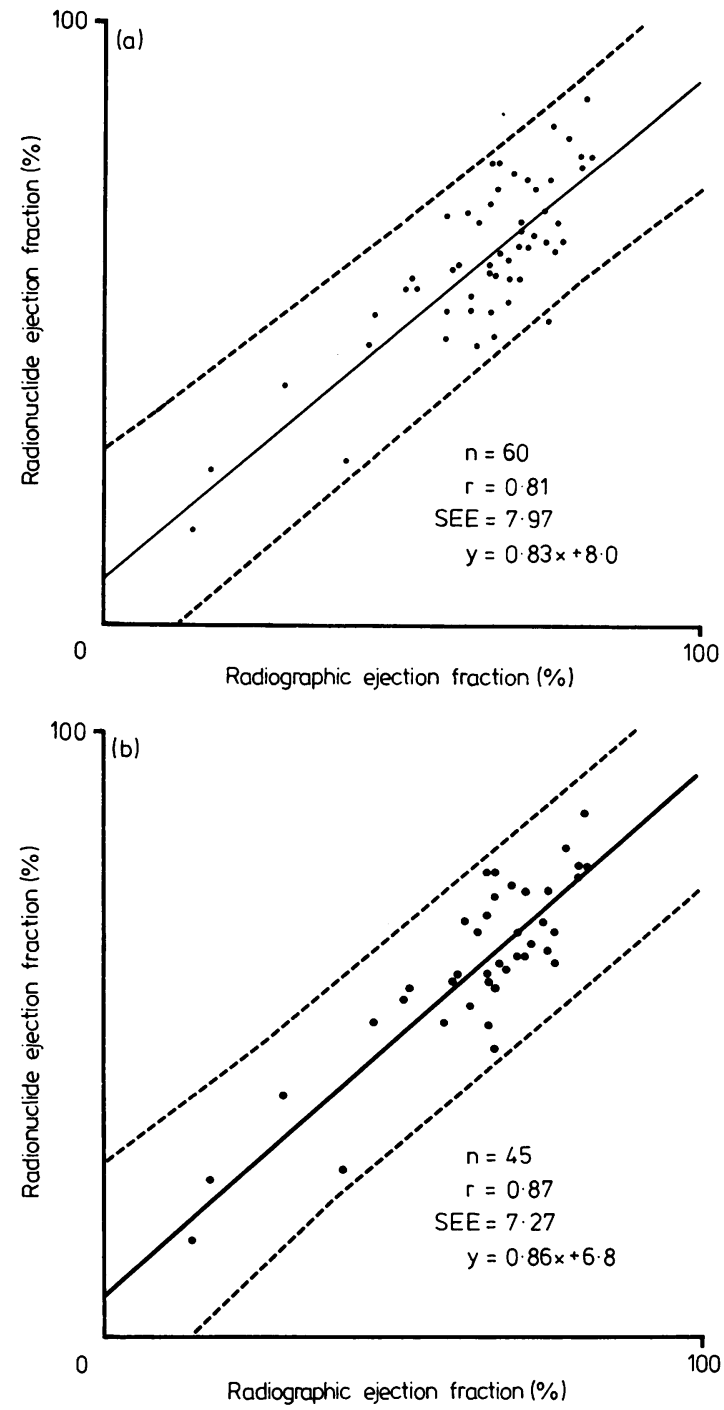

Fig. Correlation of (a) all the patients studied; and (b) the patients with no right to left shunt. The broken lines are $95 \%$ confidence limits.

\section{Results}

The results of the reproducibility study are shown in Table 3. The correlation coefficient ( $r$ ) for intraobserver reproducibility was $0.96(y=1.0 x+1.03)$ and the standard error of the estimate (SEE) was $6 \cdot 18$. For interobserver reproducibility the correlation coefficient was $0.91(y=0.95 x+5.49, \operatorname{SEE}=9 \cdot 18)$.

The correlation of the radionuclide and radiographic ejection fractions for all the patients is shown in the Figure (a). The coefficient of correlation was 
$0.81(\mathrm{p}<0.001)$, and the standard error of the estimate was 7.97.

The correlation coefficient for those infants less than 1 year old was 0.81 ( $\mathrm{SEE}=8.28)$, and the correlation was not significantly different from that for children aged more than 1 year $(r=0.80, S E E=7.73$, $p>0.1)$. The correlation coefficient for those with a small left to right shunt (Table 1), defined as a pulmonary to systemic flow ratio less than $2 \cdot 0: 1$, and no right to left shunt was $0.89(n=22, \operatorname{SEE}=7.79)$; this correlation was not significantly different from that for those with a large left to right shunt (Table 1), in whom the pulmonary to systemic flow ratio was greater or equal to $2 \cdot 0: 1 \quad(r=0.83, n=23, S E E=6.75$, $\mathrm{p}>0 \cdot 1$ ).

The analysis of those cases studied in the catheter laboratory and therefore in the closest time relation to the left ventricular cineangiogram showed a correlation coefficient of $0.90(n=12, \mathrm{SEE}=8.47)$. This correlation was not significantly different from that for the remaining 48 cases $(r=0.76, \operatorname{SEE}=7.85, p>0 \cdot 1)$.

The correlation coefficient in those patients with a right to left shunt was $0.55(y=0.60 x+19.8, n=15$, $\mathrm{SEE}=9.55$ ). Although the variance was not significantly different from that in those with no right to left shunt (Fig. (b) p>0.1), the observed correlation was poorer, and the confidence limits were wider.

Eight of the patients studied were expected on clinical grounds to have poor left ventricular function. These either had a congestive cardiomyopathy or coarctation of the aorta. If these patients and those with a right to left shunt are excluded, the mean ejection fraction was $65.7(\mathrm{SD} \pm 8 \cdot 7, \mathrm{n}=37$ ).

There was no significant correlation of ejection fraction with the pulmonary to systemic flow ratio in those patients with left to right shunts $(r=0.07$, $\mathrm{p}>0.5$ ).

\section{Discussion}

Electrocardiogram gated radionuclide angiography is a non-invasive method of measuring left ventricular ejection fraction that involves no haemodynamic disturbance to the patient and can be performed at the bedside. It is a safe procedure and the radiation dose is small. This study shows that in most cases it reflects the left ventricular performance, as measured by an invasive method, in infants and children with congenital heart disease. The correlation is not quite as good as that reported for adults, the confidence limits are wider, and the slope of the regression line approximates less well to unity. ${ }^{8911}$ The reproducibility is also not as good as in adult studies. ${ }^{1112}$

Infants and young children with congenital heart disease present special problems for the accurate and reproducible measurement of left ventricular ejection fraction by the radionuclide technique. Firstly, the count rate is lower than in adults. Secondly, the anatomical assumptions on which the technique is based may be compromised by the presence of intracardiac shunting and disordered anatomy. Thirdly, the resolution of the left ventricular outline is poorer in small hearts than in adult hearts. Nevertheless, despite these problems with the radionuclide method and also problems with the cineangiographic measurement of left ventricular volume in this age group, 1314 the correlation is sufficiently good and the confidence limits narrow enough to make it a clinically valuable technique.

The radionuclide technique has several advantages over the radiographic method. The measurement involves no geometric assumptions about the left ventricular shape. There is no question of the injection of tracer affecting the ventricular performance, as may occur with contrast media; the measured ejection fraction is the mean of many beats and premature heart beats are automatically excluded at the time of acquisition. Furthermore, simultaneous measurement of the pulmonary to systemic flow ratio is possible in those patients with left to right shunts, and a left ventricular volume curve is generated that can be used to derive other indices of left ventricular function, such as the ejection rate.

The correlation was poorest in those patients with a right to left shunt. As can be seen from Table 2, this group contained a mixture of congenital heart malformations, and it is probably not valid to consider it as a whole. Generally, these patients had the most disordered anatomy of all those studied, and they might, therefore, be expected to present the greatest problems with both techniques. With more experience it may be possible to identify which conditions among this group cause the most difficulties with the radionuclide technique. We have insufficient data for this at present.

The mean ejection fraction for these patients, excluding those with clinical left ventricular dysfunction and right to left shunts, is within the previously established normal range for older groups of patients. ${ }^{1516}$ We have not studied healthy children and so cannot quote a normal range for this age group.

Gated radionuclide angiography is a clinically valuable method of measuring left ventricular function in infants and children with congenital heart disease. Its application may improve the treatment of those patients in this age group with poor left ventricular function and enable the better selection of children for invasive investigations and cardiac surgery. The use of bedside monitoring of left ventricular function should lead to improved postoperative management after open heart surgery. Further experience will 
enable the role of left ventricular function in the long term prognosis of infants with congenital heart disease to be assessed.

EJB is a British Heart Foundation junior research fellow.

\section{References}

1 Hoffman JIE, Christianson R. Congenital heart disease in a cohort of 19,502 births with long-term follow up. Am f Cardiol 1978; 42: 641-7.

2 Maisey MN, Brennand-Roper DA, Wainwright RJ. Nuclear medicine in clinical cardiology. $\mathrm{Br}$ Med Bull 1980; 36: 237-41.

3 Kurtz D, Ahnberg DS, Freed M, LaFarge CG, Treves S. Quantitative radionuclide angiocardiography. Determination of left ventricular ejection fraction in children. Br Heart $f$ 1976; 38: 966-73.

4 Parrish MD, Graham TP Jr, Born ML, Jones J. Radionuclide evaluation of right and left ventricular function in children: validation of methodology. Am $\mathcal{Y}$ Cardiol 1982; 49: 1241-7.

5 Askenazi J, Ahnberg DS, Korngold E, LaFarge CG, Maltz DL, Treves S. Quantitative radionuclide angiocardiography: detection and quantitation of left to right shunts. Am $\mathcal{F}$ Cardiol 1976; 37: 382-7.

6 Ellam SV, Wright JGC, Maisey MN. Pitfalls in using deconvolution in the analysis of left to right shunts using first pass radioangiography. Nuclear Medicine Communications 1983; 4: 35-9.

7 Berger HJ, Matthay RA, Pytlik LM, Gottschalk A, Zaret $B L$. First-pass radionuclide assessment of right and left ventricular performance in patients with cardiac and pulmonary disease. Semin Nucl Med 1979; 9: 275-95.

8 Burow RD, Stauss HW, Singleton R, et al. Analysis of left ventricular function from multiple gated acquisition cardiac blood pool imaging. Circulation 1977; 56: 1024-8.

9 Folland ED, Hamilton GW, Larson SM, Kennedy JW, Williams DL, Ritchie JL. The radionuclide ejection fraction: a comparison of three radionuclide techniques with contrast angiography. $\mathcal{F}$ Nucl Med 1977; 18: 1159-66.

10 Dodge HT, Sandler H, Baxley WA, Hawley RR. Usefulness and limitations of radiographic methods for determining left ventricular volume. Am $\mathcal{F}$ Cardiol 1966; 18: $10-24$.

11 Karsch KR, Schicha H, Rentrop P, Kreuzer H, Emrich D. Validity of different gated equilibrium blood pool methods for determination of left ventricular ejection fraction. Eur $\mathcal{F}$ Nucl Med 1980; 5: 439-45.

12 Wackers FJT, Berger HJ, Johnstone DE, et al. Multiple gated cardiac blood pool imaging for left ventricular ejection fraction: validation of the technique and assessment of variability. Am $\mathcal{F}$ Cardiol 1979; 43: 1159-66.

13 Graham TP Jr, Jarmakani JM, Canent RV Jr, Morrow MN. Left heart volume estimation in infancy and childhood. Circulation 1971; 43: 895-904.

14 Tynan M, Reid DS, Hunter S, et al. Ejection phase indices of left ventricular performance in infants, children, and adults. $\mathrm{Br}$ Heart $\mathcal{F}$ 1975; 37: 196-202.

15 Upton MT, Rerych SK, Newman GE, Bounous EP Jr, Jones RH. The reproducibility of radionuclide angiographic measurements of left ventricular function in normal subjects at rest and during exercise. Circulation 1980; 62: $126-32$.

16 Kennedy JW, Baxley WA, Figley MM, Dodge HT, Blackmon JR, Quantitative angiocardiography: 1. The normal left ventricle in man. Circulation 1966; 34: 272-8. 